\title{
Lomiphene citrate versus letrozole as first line ovulation induction drug in infertile anovulatory polycystic ovarian syndrome women: a prospective randomized controlled trial
}

\author{
Monica Soni, Jeevika Gupta*, Arti Meena
}

Department of Obstetrics and Gynecology, SPMC, Bikaner, Rajasthan, India

\author{
Received: 27 March 2020 \\ Accepted: 29 April 2020 \\ *Correspondence: \\ Dr. Jeevika Gupta, \\ E-mail: jeevikagupta23113@gmail.com
}

Copyright: () the author(s), publisher and licensee Medip Academy. This is an open-access article distributed under the terms of the Creative Commons Attribution Non-Commercial License, which permits unrestricted non-commercial use, distribution, and reproduction in any medium, provided the original work is properly cited.

\begin{abstract}
Background: The present study was design to compare letrozole $(5 \mathrm{mg})$ and clomiphene citrate (100 $\mathrm{mg})$ as first line ovulation induction drug in infertile anovulatory polycystic ovarian syndrome (PCOS) women.

Methods: This prospective randomized clinical trial included 60 cases of PCOS with anovulatory infertility. The first group comprised of 30 patients who received $5 \mathrm{mg}$ letrozole daily and the second group received $100 \mathrm{mg}$ clomiphene citrate daily for 5 days starting on day 2-5 of menses. Both the groups were followed by ultrasound for follicle monitoring, ovulation and endometrial thickness. When dominant follicle reaches a diameter of more than or equal to $18 \mathrm{~mm}$ and endometrial thickness $\geq 7.5 \mathrm{~mm}$, human chorionic gonadotrophin (hCG) 5,000 IU was given intramuscularly and timed intercourse was advised. Main outcome measures were occurrence of ovulation, endometrial thickness and pregnancy rates.

Results: The mean age, body mass index, and number of cases of primary and secondary infertility in both the groups showed no statistically significant difference. Multi-follicular development during induction was statistically significantly greater in the clomiphene group $(1.27 \pm 1.11$ versus $2.03 \pm 1.65 ; \mathrm{p}=0.041)$. Ovulation occurred in 24 subjects $(80 \%)$ in letrozole group and 18 subjects $(60 \%)$ in the clomiphene group, with a statistically significant difference between the two groups $(\mathrm{p}=0.024)$. Pregnancy occurred in 16 subjects $(53.33 \%)$ in letrozole group and 7 subjects $(23.33 \%)$ in clomiphene group, which shows statistically significant difference between the two groups $(\mathrm{p}=0.048)$.

Conclusions: Though number of developing follicles was found statistically significant with clomiphene citrate but ovulation rate and pregnancy rate were higher with letrozole group. Therefore, letrozole is a safe and better alternative for ovulation induction in patients of anovulatory PCOS, and it may be considered as a first line treatment for ovulation induction in these patients.
\end{abstract}

Keywords: Anovulatory infertility, Clomiphene citrate, Letrozole, Polycystic ovarian syndrome

\section{INTRODUCTION}

Polycystic ovarian syndrome (PCOS) is the most common cause of anovulatory infertility and is responsible for up to $70 \%$ of cases of infertility due to anovulation. ${ }^{1}$ It is well known that polycystic ovarian syndrome is among the most common endocrine disorders in women of reproductive age and has a strong genetic component. It is characterized by ovarian dysfunction, and its clinical manifestations may include obesity, increased insulin resistance and compensatory hyperinsulinemia, hyperandrogenism, oligomenorrhea or amenorrhea, anovulation and infertility. ${ }^{2}$

It has been recognized that PCOS has an extremely heterogenous picture and is multifactorial in etiology. 
The diagnosis of PCOS is commonly based on the Rotterdam criteria which requires the presence of any two of the following:

- Chronic oligo/anovulation

- Clinical/biochemical parameters for hyperandrogenism

- Polycystic ovaries on ultrasonography and exclusion of other etiologies (congenital adrenal hyperplasia, androgen-secreting tumors, Cushing syndrome) etc. ${ }^{3}$

Infertility is a unique medical condition, in that it is a disorder that often involves a couple, not an individual. An infertile couple is one that has been unable to conceive in one year of unprotected intercourse. It is subdivided into primary and secondary. ${ }^{4}$ Primary infertility applies to those who have never conceived while secondary infertility is designated to those who have conceived at some time in the past.

Clomiphene citrate has traditionally been the standard drug for inducing ovulation. It is not, however, equally successful in all situations. Dichotomy in ovulation and conception rates has been an issue. Anti-oestrogenic effects on endometrium and cervical mucus have been reported. Alternative treatments to clomiphene citrate with aromatase inhibitors such as letrozole have attracted attention.

Clomiphene, a non-steroidal compound, structurally similar to estrogen, blocks estrogenic hypothalamic receptors, resulting in blinding of the hypothalamus pituitary axis to endogenous circulating estrogen. This in turn triggers the release of $\mathrm{FSH}$ from the anterior pituitary following alterations in GnRH pulsality. Clomiphene also has peripheral anti-estrogenic action at the level of endometrium and cervical mucus, partly explaining the discrepancy in ovulation rates and pregnancy rates. $^{5}$

Letrozole, a selective aromatase inhibitor, prevents the conversion of androgens to estrogen, thus releasing the hypothalmo-pituitary axis from the negative feedback of estrogen, resulting in an increase of FSH secretion from the anterior pituitary. Letrozole is devoid of any anti estrogenic peripheral action. The accumulated androgens in the ovary further increase follicular sensitivity to $\mathrm{FSH}^{6}$

The aim of the study is to compare between the use of letrozole and clomiphene citrate in women with polycystic ovarian syndrome undergoing ovarian stimulation and to evaluate the ovulation and pregnancy rate between the two groups.

\section{METHODS}

This prospective clinical trial was conducted at the infertility clinic of Janana Hospital, PBM hospital, SPMC Bikaner, Rajasthan from January 2019 to December 2019. The patients were counselled and screened before randomization. Sixty women were selected from those who were attending the infertility clinic with anovulatory infertility.

\section{Inclusion criteria}

- $\quad$ Age between 20-35

- Primary or secondary infertility

- Patients diagnosed with PCOS according to Rotterdam criteria.

\section{Exclusion criteria}

- Patients having any cause of infertility other than PCOS

- Hyperprolactinemia

- Ovarian cysts $>4 \mathrm{cms}$ on baseline scan

- Male factor infertility

- Thyroid dysfunction

- Diabetes mellitus or other medical disorders

- Known or suspected tubal factor by HSG or laparoscopic chromotubation

- Endometriosis or pelvic inflammatory disease

- Contraindication to either drug

- Known sensitivity to either drug.

The patients were randomly divided into two groups. Baseline ultrasound was done. Screening for ovarian cyst was done. Thirty patients received letrozole with a starting dose of $5 \mathrm{mg}$ for 5 days starting from the 3-5 day of a menstrual bleeding. Thirty patients had received CC with a starting dose of $100 \mathrm{mg}$ daily for 5 days beginning on day 2-5 of the menstrual cycle. Follicular development was monitored using serial ultrasound from day 9 onwards until a mature follicle of diameter $\geq 18 \mathrm{~mm}$ and trilaminar layer of endometrial pattern were seen. Injection hCG 5,000 IU intramuscularly was given to the patients when a dominant follicle of diameter of $\geq 18 \mathrm{~mm}$ and $\mathrm{ET} \geq 7.5 \mathrm{~mm}$ was observed.

The subsequent scan was performed after 48 hours of injection of (hCG) to observe the release of ova. Ovulation was ascertained by observing the rupture of the follicle by ultrasound and free fluid in Pouch of Douglas. Each woman was asked to have timed intercourse for 3 days after the ovulatory dose of hCG. Chemical pregnancy was assessed by the serum level of beta-hCG measurement once the patient missed her period. Documentation of at least one gestational sac in USG was confirmed as clinical pregnancy. The mean number of follicles, endometrial thickness, ovulatory cycle rate, conception rate and pregnancy outcome were compared in both the groups.

\section{Statistical analysis}

Statistical analysis was done using SPSS software. Results were expressed as mean and standard errors of mean. The $\mathrm{p}$ value of $<0.05$ was considered statistically 
significant. The work was approved by the local ethical committee.

\section{RESULTS}

During the study period. A total of 60 cases were taken who met the inclusion criteria. There was no statistically significant difference between the two groups in age, body mass index, and number of cases of primary and secondary infertility. However, mean duration of infertility was found to be greater in clomiphene group $(2.80 \pm 2.06)$ as compared to letrozole group $(2.67 \pm 1.90)$ which is statistically significant $(\mathrm{p}=0.0001)$ (Table 1$)$.

The total number of follicles during induction was statistically significantly greater in the clomiphene group
(1.27 \pm 1.11 versus $2.03 \pm 1.65 ; \mathrm{p}=0.041)$. Ovulation occurred in 24 subjects $(80 \%)$ in letrozole group and 18 subjects $(60 \%)$ in the clomiphene group, with a statistically significant difference between the two groups $(\mathrm{p}=0.024)$. There was no statistically significant difference in endometrial thickness between the two groups.

Pregnancy occurred in 16 subjects $(53.33 \%)$ in letrozole group and 7 subjects $(23.33 \%)$ in clomiphene citrate group, which shows statistically significant difference between the two groups $(\mathrm{p}=0.048)$ (Table 2).

No major side effects were seen with both the drugs except for ovarian cyst seen in 3 subjects in clomiphene group. No such case was reported in letrozole group.

Table 1: Patient characteristics.

\begin{tabular}{|llll|}
\hline & Group A & Group B & p value \\
\hline Age $($ years $)$ & $25.23 \pm 4.22$ & $24.30 \pm 4.13$ & 0.392 \\
\hline BMI $\left(\mathrm{kg} / \mathrm{m}^{2}\right)$ & $23.55 \pm 3.67$ & $23.18 \pm 3.86$ & 0.705 \\
\hline Duration of infertility & $2.67 \pm 1.90$ & $2.80 \pm 2.06$ & 0.0001 \\
\hline Primary infertility & 19 & 17 & 0.958 \\
\hline Secondary infertility & 11 & 13 & 0.918 \\
\hline
\end{tabular}

Table 2: Outcomes parameters.

\begin{tabular}{|llll|}
\hline & Group A (letrozole) & Group B (clomiphene citrate) & p value \\
\hline Total number of follicles & $1.27 \pm 1.11$ & $2.03 \pm 1.65$ & 0.041 \\
\hline Ovulation & 24 & 18 & 0.024 \\
\hline $\begin{array}{l}\text { Endometrial thickness at the } \\
\text { time of hCG administration }\end{array}$ & $7.41 \pm 1.20$ & $7.35 \pm 1.39$ & 0.890 \\
\hline Pregnancy & 16 & 7 & 0.048 \\
\hline
\end{tabular}

\section{DISCUSSION}

The first line of ovulation inducing agent clomiphene citrate is not equally effective in all situations for induction of ovulation or superovulation. The use of CC may be associated with poor cervical mucous and endometrial thinning in $15-20 \%$ of patients due to prolonged estrogen receptor depletion in the endometrium and possibly in the cervix. ${ }^{7-11}$ Clomiphene citrate, which is the most commonly prescribed medication, initiates ovulation by blocking the negative feedback of endogenous estrogen at the level of hypothalamus-pituitary promoting pulsatile release of $\mathrm{LH}$ and FSH in anovulatory patients with PCOS. ${ }^{12}$ For many years, clomiphene citrate has been used as the standard drug for ovulation induction in PCOS. ${ }^{13}$ But up to $58 \%$ patients are resistant to it and do not ovulate. ${ }^{14} \mathrm{CC}$ has an antagonistic effect on the endometrium and may reduce endometrial thickness. ${ }^{15}$ The inappropriate development of endometrium is associated with a low implantation rate and early pregnancy loss caused by luteal phase defect. ${ }^{16}$
Letrozole is a type IIa third-generation aromatase inhibitor. It was postulated that blocking estrogen production by inhibiting aromatization, the conversion of androstenedione and testosterone to estrogen in the ovary would release FSH/LH from the hypothalmic/pituitary axis by inhibiting estrogenic negative feedback. As a result, the FSH secretion increases, stimulating the development of ovarian follicles. Mitwally and Casper described the use of $2.5 \mathrm{mg}$ of letrozole on das 3-7 of menses in 12 patients with PCOS. ${ }^{14}$ Ovulation occurred in nine patients $(75 \%)$, and pregnancy was achieved in 3 (25\%). Sammour et al, found in their double-blind randomized trial comparing the use of an aromatase inhibitor with CC for stimulation in 49 women with infertility that increased endometrial thickness compared with those receiving $\mathrm{CC}$, because threefold increase in the PR was observed in the patients who received aromatase inhibitor compared with CC treatment. ${ }^{17}$

When compared, clomiphene showed statistically significant increase in the number of developing follicles 
and mature follicles. But favorable pregnancy outcomes were seen with letrozole. The antagonistic effect of clomiphene citrate on endometrium may reduce endometrial thickness and possibly explains lower pregnancy rate.

\section{CONCLUSION}

In conclusion, this study results of randomized trial suggests that letrozole is as good as clomiphene citrate. Though number of developing follicles was found statistically significant with clomiphene citrate but ovulation rate and pregnancy rate were higher with letrozole group. Therefore, letrozole is a safe and better alternative to clomiphene citrate in ovulation induction protocol for patients of anovulatory PCOS, and it may be considered as a first line treatment for ovulation induction in these patients.

Funding: No funding sources Conflict of interest: None declared

Ethical approval: The study was approved by the Institutional Ethics Committee

\section{REFERENCES}

1. Fleming R, Hopkinson ZE, Wallace AM, Greer IA, Sattar N. Ovarian function and metabolic factors in women with oligomenorrhea treated with metformin in a randomized double-blind placebo-controlled trial. J Clin Endocrinol Metab. 2002;87:5.

2. The Rotterdam ESHRE/ASRM-Sponsored PCOS Consensus on diagnostic criteria and long- term health risks related to polycystic ovary syndrome. Fertil Steril. 2004;81:19-25.

3. Saxena P, Prakash A, Ngam A, Mishra A. Polycystic ovary syndrome: Is obesity a sine qua non? A clinical, hormonal, and metabolic assessment in relation to body mass index. Indian $\mathrm{J}$ Endomcrinol Metab. 2012;16:996-9.

4. Dor J, Lerner-Geva L, Rabinovici J, Chetrit A, Levran D, Lunenfeld B, et al. Cancer incidence in a cohort of infertile women who underwent in vitro fertilization. Fertil Steril. 2002;77:324-7.

5. Homburg R. Comiphene citrate-end of an era? A mini review. Hum Reprod. 2005;20:2043-51.

6. Holzer H, Casper R, Tulandi T. A new era in ovulation induction. Fertil Steril. 2006;85:277-84.

7. Gonen Y, Casper RE. Sonographic determination of a possible adverse effect of clomiphene citrate on endometrial growth. Hum Reprod. 1990;5:670-4.

8. Yagel S, Ben-Chetrit A, Anteby E, Zacut D, Hochner-Celnikter D, Ron M. The effect of ethinyl estradiol on endometrial thickness and uterine volume during ovulation induction by clomiphene citrate. Fertil Streil. 1992;57:33-6.

9. Dicke RP, Olar TT, Taylor SN, Curole DN, Matulich EM. Relationship of endometrial thickness and pattern to fecundity in ovulation induction cycles: effect of clomiphene citrate alone and with human menopausal gonadotrophin. Fertil Steril. 1993;59:756-60.

10. Opsahl MS, Robins ED, O'Conner DM, Scott RT, Fritz MA. Characteristics of gonadotropin response, follicular development, and endometrial growth and maturation across consecutive cycles of clomiphene citrate treatment. Fertil Steril. 1996;66:533-9.

11. Eden JA, Place J, Carter GD, Jones J, AlaghbandZadeh J, Pawson ME. The effect of clomiphene citrate on follicular phase increase endometrial thickness and uterine volume. Obstet Gynecol. 1989;73:187-90.

12. Kettel LM, Roseff SJ, Berga SL. Hypthalamuspituitary-ovarian response tp clomiphene citrate in women with polycystic ovary syndrome. Fertil Steril. 1993;59:532-8.

13. Franks S. Polycystic ovary syndrome. N Eng J Med. 1995;333:853-61.

14. Mitwally MF, Casper RF. Use of an aromatase inhibitor for induction of ovulation in patients with an inadequate response to clomiphene citrate. Fertil Steril. 2001;75:305-9.

15. Nakamura $Y$, Ono M, Yoshida Y. Effect of clomiphene citatre on endometrial thickness and echogenic pattern of the endometrium. Fertil Steril. 1997;67:256-60.

16. Randall JM, Templeto A. Cervical mucus score and in vitro sperm mucus interaction in spontaneous and clomiphene citrate cycles. Fertil Steril. 1991;56:4658.

17. Sammour A, Biljan MM, Tan SL, Tulandi T. Prospective randomised trial comparing the effects of letrozole and clomiphene citrate (CC) on follicular development, endometrial thickness and pregnancy rate in patients undergoing superovulation prior to intrauterine insemination. $57^{\text {th }}$ Annual Meeting of the American Society for Reproductive Medicine. Fertil Steril. 2001;76(suppl 1):S110.

Cite this article as: Soni M, Gupta J, Meena A. Lomiphene citrate versus letrozole as first line ovulation induction drug in infertile anovulatory polycystic ovarian syndrome women: a prospective randomized controlled trial. Int J Reprod Contracept Obstet Gynecol 2020;9:2512-5. 